\title{
Selective inhibition of plasma membrane calcium ATPase 4 improves angiogenesis and vascular reperfusion
}

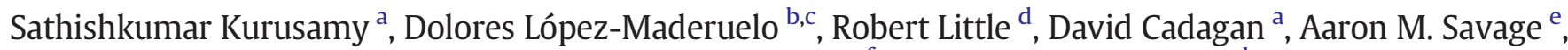 \\ Jude C. Ihugba ${ }^{\text {a }}$, Rhiannon R. Baggott ${ }^{\text {a }}$, Farjana B. Rowther ${ }^{\mathrm{f}}$, Sara Martínez-Martínez ${ }^{\mathrm{b}, \mathrm{c}}$, \\ Pablo Gómez-del Arco b,c,g, Clare Murcott ${ }^{\mathrm{a}}$, Weiguang Wang ${ }^{\mathrm{h}}$, J. Francisco Nistal ${ }^{\mathrm{i}}$, Delvac Oceandy ${ }^{\mathrm{d}}$, \\ Ludwig Neyses ${ }^{\mathrm{d}, \mathrm{j}}$, Robert N. Wilkinson ${ }^{\mathrm{e}}$, Elizabeth J. Cartwright ${ }^{\mathrm{d}}$, \\ Juan Miguel Redondo ${ }^{\mathrm{b}, \mathrm{c}, *}$, Angel Luis Armesilla ${ }^{\mathrm{a}, \mathrm{c}, * *}$ \\ a Cardiovascular Molecular Pharmacology Laboratory, School of Pharmacy, University of Wolverhampton, Wolverhampton, UK \\ b Gene Regulation in Cardiovascular Remodelling and Inflammation Group, Centro Nacional de Investigaciones Cardiovasculares Carlos III (CNIC), Madrid, Spain \\ c CIBERCV, Spain \\ ${ }^{\mathrm{d}}$ Division of Cardiovascular Sciences, University of Manchester, Manchester Academic Health Sciences Centre, Manchester, UK \\ e Department of Infection, Immunity \&' Cardiovascular Disease \&' Bateson Centre, University of Sheffield, UK \\ ${ }^{\mathrm{f}}$ Brain Tumor UK Neuro-oncology Research Centre, University of Wolverhampton, Wolverhampton, UK \\ ${ }^{g}$ Department of Molecular Biology, Universidad Autonoma de Madrid (C.B.M.S.O.), Madrid, Spain

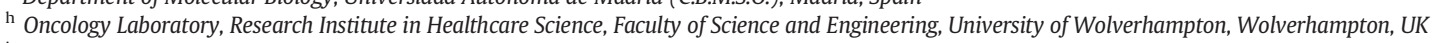

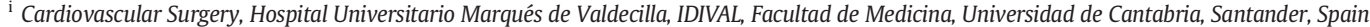 \\ ${ }^{\mathrm{j}}$ University of Luxembourg, Luxembourg
}

\section{A R T I C L E I N F O}

\section{Article history:}

Received 16 February 2017

Received in revised form 12 June 2017

Accepted 3 July 2017

Available online 3 July 2017

\section{Keywords:}

PMCA4

Angiogenesis

ATA

Calcineurin/NFAT

VEGF

\begin{abstract}
A B S T R A C T
Aims: Ischaemic cardiovascular disease is a major cause of morbidity and mortality worldwide. Despite promising results from pre-clinical animal models, VEGF-based strategies for therapeutic angiogenesis have yet to achieve successful reperfusion of ischaemic tissues in patients. Failure to restore efficient VEGF activity in the ischaemic organ remains a major problem in current pro-angiogenic therapeutic approaches. Plasma membrane calcium ATPase 4 (PMCA4) negatively regulates VEGF-activated angiogenesis via inhibition of the calcineurin/NFAT signalling pathway. PMCA4 activity is inhibited by the small molecule aurintricarboxylic acid (ATA). We hypothesize that inhibition of PMCA4 with ATA might enhance VEGF-induced angiogenesis.

Methods and results: We show that inhibition of PMCA4 with ATA in endothelial cells triggers a marked increase in VEGF-activated calcineurin/NFAT signalling that translates into a strong increase in endothelial cell motility and blood vessel formation. ATA enhances VEGF-induced calcineurin signalling by disrupting the interaction between PMCA4 and calcineurin at the endothelial-cell membrane. ATA concentrations at the nanomolar range, that efficiently inhibit PMCA4, had no deleterious effect on endothelial-cell viability or zebrafish embryonic development. However, high ATA concentrations at the micromolar level impaired endothelial cell viability and tubular morphogenesis, and were associated with toxicity in zebrafish embryos. In mice undergoing experimentally-induced hindlimb ischaemia, ATA treatment significantly increased the reperfusion of post-ischaemic limbs.

Conclusions: Our study provides evidence for the therapeutic potential of targeting PMCA4 to improve VEGFbased pro-angiogenic interventions. This goal will require the development of refined, highly selective versions of ATA, or the identification of novel PMCA4 inhibitors.
\end{abstract}

(c) 2017 Elsevier Ltd. All rights reserved.

\footnotetext{
* Correspondence to: J.M. Redondo, Gene Regulation in Cardiovascular Remodelling and Inflammation Group, Centro Nacional de Investigaciones Cardiovasculares, Melchor Fernandez Almagro 3, E-28029 Madrid, Spain.

** Correspondence to: A.L. Armesilla, Cardiovascular Molecular Pharmacology Laboratory, Research Institute in Healthcare Science, School of Pharmacy, Faculty of Science and Engineering, University of Wolverhampton, Wulfruna Street, Wolverhampton WV1 1SB, UK.

E-mail addresses: jmredondo@cnic.es (J.M. Redondo), A.Armesilla@wlv.ac.uk (A.L. Armesilla).
}

\section{Introduction}

Ischaemic cardiovascular diseases (including ischaemic heart disease, peripheral arterial disease, and stroke) constitute a leading cause of morbidity and mortality worldwide [28]. In some patients, bypass surgery and interventional endovascular procedures can successfully restore blood flow to the ischaemic tissue [1,33]. However, the 
distribution and diffuseness of arterial occlusions preclude surgical revascularization in a high proportion of patients [1]. Therapeutic strategies to promote the formation of new blood vessels in the ischaemic organ (referred to as therapeutic angiogenesis) constitute a promising alternative for these patients $[1,11,42]$.

Angiogenesis, the formation of new blood vessels from preexisting ones, is a tightly regulated process involving the participation of several pro- and anti-angiogenic factors [10]. One of the critical pro-angiogenic factors is vascular endothelial growth factor (VEGF) [38]. A number of gene-based and protein-based approaches have been developed to deliver exogenous VEGF to ischaemic tissues [42]. Data obtained in animal models of myocardial and limb ischaemic disease demonstrated that VEGF-based pro-angiogenic therapies induce successful reperfusion of the ischaemic organ [40]. Unfortunately, to date clinical translation of these procedures has produced only limited patient benefit [12]. The reasons for the lack of clinical success with therapeutic angiogenesis approaches are complex, but one central problem in current approaches is failure to restore efficient VEGF activity in the ischaemic organ [12,40,42]. Design of new, more effective treatments requires a deep understanding of the molecular and biochemical processes governing VEGF-induced angiogenesis.

We recently reported a novel role for plasma membrane calcium ATPase 4 (PMCA4) as a negative regulator of VEGF-activated angiogenesis [4]. PMCAs are enzymatic high-affinity systems that export calcium from the cytosol to the extracellular environment [37]. There are four PMCA isoforms (PMCA1-4) encoded by four distinct genes [37]. PMCA1 and 4 are expressed ubiquitously, whereas PMCA2 and 3 are restricted to highly specialised cells and tissues [37]. PMCA4 is the major isoform present in endothelial cells [30]. Our previous work showed that PMCA4 attenuates VEGF-induced angiogenesis by establishing an inhibitory interaction with the signalling protein calcineurin [4]. Calcineurin is a serine/threonine phosphatase activated by increases in cytosolic calcium concentration [20]. Activated calcineurin mediates dephosphorylation of NFAT (nuclear factor of activated T cells) transcription factors, promoting their translocation to the nucleus and the subsequent expression of NFAT-target genes [15]. The calcineurin/NFAT signalling axis plays a critical role in VEGF-induced angiogenesis [2,14]. PMCA4 is thought to downregulate calcineurin activity by tethering it to low-calcium micro-domains created by the pump's calcium expulsion action and, in so doing, impair VEGF-activated pro-angiogenic signalling [4]. We therefore hypothesize that pharmacological blockade of PMCA4 function, and thus suppression of the negative effect of PMCA4 on angiogenesis, might potentiate the efficiency of therapeutic strategies involving VEGF. Supporting this possibility, we previously reported more efficient limb reperfusion in PMCA4 ${ }^{-1-}$ knockout mice undergoing femoral artery ligation than in their wildtype littermates [4].

A recent study showed that low concentrations of the small molecule aurintricarboxylic acid (ATA) strongly inhibit the calcium extrusion activity of PMCA4 without affecting the activity of PMCA1 or other major calcium pumps such as SERCA and the $\mathrm{Na}^{+} / \mathrm{K}^{+}$ATPase [26]. This finding prompted us to examine whether inhibition of PMCA4 with ATA enhances VEGF-induced angiogenesis.

Here, we show that treatment of primary endothelial cells with low concentrations of ATA results in a remarkable increase in VEGF-mediated activation of the calcineurin/NFAT pathway and in the expression of the VEGF-induced, NFAT-dependent, pro-angiogenic protein RCAN1.4. Inhibition of PMCA4 with ATA also enhances endothelial cell motility and tubular morphogenesis, with no harmful effects on the cells. These results highlight the clinical potential of targeting PMCA4 to improve VEGF-based therapeutic interventions that promote blood vessel formation in patients suffering from ischaemic cardiovascular disease.

\section{Materials and methods}

\subsection{Cells and cell culture}

Human umbilical vein endothelial cells (HUVEC) were purchased from TCS Cellworks and cultured in tissue culture flasks pre-coated with $0.1 \%$ gelatin in endothelial cell growth medium (ECGM, PromoCell) supplemented with ECGM-supplement mix and $1 \%$ penicillin/streptomycin/amphotericin B (Sigma-Aldrich). HUVECs were used at passages 6-8.

Mouse lung endothelial cells (MLEC) were purified from wild-type or PMCA4-null mice as described [4]. Generation and characterization of PMCA4 knockout mice has been previously reported [34].

\subsection{Luciferase reporter assay}

HUVECs were infected with Ad-NFAT-Luc (a replication-deficient adenovirus harbouring an NFAT-dependent, luciferase-based reporter system) at a multiplicity of infection (MOI) of 50. Generation of AdNFAT-Luc-infected particles was as described [4]. Infected cells were incubated in ECGM containing $0.5 \%$ fetal calf serum for $16 \mathrm{~h}$ and then stimulated with VEGF (25 ng/ml) for $6 \mathrm{~h}$. Luciferase activity was determined as described [17].

\section{3. siRNA gene knock-down}

siRNA-mediated knock-down of PMCA4 gene expression was performed using "ON-TARGET-plus SMART pool human ATP2B4" (Thermo Scientific). "ON-TARGET-plus non-targeting pool control duplexes" (Thermo Scientific) was used as a control.

For siRNA transfection, HUVECs were plated in $0.1 \%$ gelatin pre-coated 6 -well tissue culture plates $\left(3 \times 10^{5}\right.$ cells/well) and incubated overnight. The following morning, cells were washed with PBS and incubated in serum-free, antibiotic-free OPTIMEM medium for $1 \mathrm{~h}$. Then, $100 \mathrm{pmol}$ of siRNA/well were transfected using $5 \mu$ of Lipofectamine 2000 (Thermo Scientific). Transfection medium was removed after incubation for $6 \mathrm{~h}$, and substituted by ECGM supplemented with ECGM-supplement mix and 1\% penicillin/streptomycin/amphotericin B (Sigma-Aldrich). Cells were incubated for $72 \mathrm{~h}$ and then used for further experiments.

\subsection{Quantitative Real-Time PCR}

Total RNA from HUVECs was extracted using the "Total RNA purification kit" (Norgen) and cDNA synthesis was performed with $0.5 \mu \mathrm{g}$ of total RNA using the "High capacity cDNA reverse transcription kit" (Applied Biosystems). PMCA4 RNA expression was determined by qRT-PCR using TaqMan Gene Expression Assay (Hs00608066_m1) in a 7500 Fast Real-Time PCR System (Applied Biosystems, UK). PCR cycling conditions consisted of an initial enzyme activation step at $95^{\circ} \mathrm{C}$ for $10 \mathrm{~min}$, followed by denaturation at $95^{\circ} \mathrm{C}$ for $15 \mathrm{~s}$, and annealing and extension at 60 ${ }^{\circ} \mathrm{C}$ for $1 \mathrm{~min}$ for 40 cycles. $\mathrm{Ct}$ value was normalised using the $\mathrm{Ct}$ values for the housekeeping gene Hprt-1 (TaqMan Gene Expression Assay, Hs99999909_m1). Analysis of data was carried out using the comparative $2^{-\Delta \Delta C T}$ method.

\subsection{Western blot}

Total proteins were isolated by direct lysis of HUVECs, treated as indicated, in NuPAGE LDS sample buffer containing $0.05 \% \beta$ mercaptoethanol. Membrane-associated proteins were isolated using the ProteoExtract Subcellular Proteome Extraction Kit (Calbiochem) as reported [3].

We have noticed that repeated and prolonged boiling degrades endothelial PMCA4; therefore we minimised repeated cycles of freezethawing-boiling. Protein samples were boiled for $1 \mathrm{~min}$ and then 
resolved by SDS-PAGE as described [9]. Antibody sources and conditions are described in detail in the online Supplementary material.

\subsection{Immunoprecipitation}

HUVECs were stimulated for $4 \mathrm{~h}$ with VEGF $(25 \mathrm{ng} / \mathrm{ml})$ in the presence of ATA ( $250 \mathrm{nM}$ ) or vehicle (DMSO), and PMCA4/calcineurin complexes were immunoprecipitated from $4 \mathrm{mg}$ total protein extract with anti-calcineurin A monoclonal antibody (Sigma) using the Pierce Co-Immunoprecipitation Kit. To immunoprecipitate the PMCA4/eNOS complex, the same conditions were used except that cells were treated for only $5 \mathrm{~min}$ and protein lysates were incubated with anti-PMCA 5F10 monoclonal antibody.

Levels of PMCA4, calcineurin, or eNOS in the immunoprecipitates were determined by western blot using anti-PMCA4 (JA3), anti-calcineurin A, or anti-eNOS antibodies.

\subsection{Wound healing migration assay}

Cell migration of HUVECs and MLECs, treated as indicated, was assayed using the Cytoselect ${ }^{\mathrm{TM}}$ 24-well Wound Healing Assay kit (Cell Biolabs). Images were captured with a Nikon DSFi1 digital camera coupled to a Nikon ECLIPSE TS100 microscope at $4 \times$ magnification. Cell-free area was quantified with ImageJ software.

\subsection{Matrigel tube-formation assay}

HUVECs were plated onto Geltrex Reduced Growth-Factor Matrix (Invitrogen) in Medium 200 with no phenol red and supplemented with $2 \%$ fetal calf serum and $50 \mathrm{ng} / \mathrm{ml}$ growth factor (VEGF or bFGF) in the presence of ATA at the indicated concentration or DMSO as a control. Tube formation was quantified after incubation at $37^{\circ} \mathrm{C}$ for $16 \mathrm{~h}$. Images were recorded with a Nikon DSFi1 digital camera coupled to a Nikon ECLIPSE TS100 microscope at $4 \times$ magnification.

\subsection{MTT assay}

HUVECs were seeded on 96-well tissue culture plates (without gelatin pre-coating) at a density of $2.5 \times 10^{4}$ cells/well in supplemented ECGM (PromoCell). Cell viability was determined by MTT assay [31] the morning after cell plating (Time $=0$ ) and then after 3 and 6 days of incubation in supplemented ECGM containing VEGF $(25 \mathrm{ng} / \mathrm{ml})$ and ATA at the indicated concentration or DMSO as control.

\subsection{Zebrafish embryo viability}

Zebrafish embryos Tg(kdrl:HRAS-mCherry; flk1:EGFP-nls) [7,16] were manually dechorionated and incubated in increasing concentrations of ATA or DMSO from 30 hour post fertilisation (hpf) for $24 \mathrm{~h}$. Vascular morphology was imaged at 54 hpf using a Zeiss Lightsheet Z.1 microscope. Experiments were performed under UK Home Office licence $40 / 3708$.

\subsection{Murine hindlimb ischaemia}

Unilateral hindlimb ischaemia was induced by femoral artery ligation in 12-week-old C57/BL6 mice anaesthetised with $2 \%$ isoflurane via inhalation. To induce hindlimb ischaemia maintaining minimal blood flow to the limb, we ligated a short fragment of the femoral artery in proximal and distal positions and excised the intervening segment (this procedure corresponds to the experiments shown in Fig. 7). In a separate set of experiments, to totally blunt blood flow to the limb, we performed femoral ligation and excision of the intervening segment but on this occasion we ligated and excised a longer femoral segment to induce deep acute ischaemia (this procedure corresponds to the experiments shown in Fig. S5). In all cases, ATA (5 mg/kg) or DMSO (vehicle) was administered intraperitoneally $2 \mathrm{~h}$ after the operation, and then daily as indicated. Blood flow was measured in the sham-operated and ischaemic limbs of anaesthetised animals before surgery, $2 \mathrm{~h}$ after the operation, and at the indicated times using a Laser Doppler Perfusion Imager System (Moor Instruments). Mice were sacrificed in an euthanasia chamber with $70 \% \mathrm{CO}_{2}$.

Mouse studies were approved by Animal Care and Ethics committee at the Centro Nacional de Investigaciones Cardiovasculares and conformed to directive 2010/63EU and recommendation 2007/562/EC regarding the protection of animals used for experimental and other scientific purposes.

\subsection{Nitric oxide determination}

To determine intracellular nitric oxide bioavailability HUVECs were incubated for $3 \mathrm{~h}$ in basal ECGM (Promocell) containing 0.5\% fetal bovine serum (FBS). After serum starvation, L-arginine was added to a $100 \mu \mathrm{M}$ final concentration and cells were incubated for $15 \mathrm{~min}$. Cells were then loaded for $30 \mathrm{~min}$ with $10 \mu \mathrm{M}$ of the NO-sensitive fluorescence probe DAF-FM (Molecular Probes). Dye-containing medium was removed and replaced with basal ECGM, 0.5\% FBS. Cells were incubated for $45 \mathrm{~min}$ at $37^{\circ} \mathrm{C}$, and then NO synthesis was induced by stimulation for $5 \mathrm{~min}$ with VEGF ( $25 \mathrm{ng} / \mathrm{ml}$ ) in the presence of ATA ( $250 \mathrm{nM}$ ) or vehicle (DMSO). After treatment, cells were washed with PBS and fixed in formalin (Sigma). DAF-FM fluorescence was detected using a ZEISS LSM 880 confocal laser scanning microscope.

\subsection{Immunohistochemistry}

Tibialis muscle isolated from non-ischaemic (sham-operated) or ischaemic limbs were fixed in $4 \%$ formalin solution, then incubated in $30 \%$ saccharose solution, embedded in OCT, frozen in liquid nitrogen, and finally cut on a cryotome. VEGF expression was detected by immunohistochemistry using a 1:750 dilution of an anti-VEGF-A rabbit polyclonal antibody ( $1 \mathrm{mg} / \mathrm{ml}$, Sigma-Aldrich). A biotinylated anti-rabbit IgG was used as secondary antibody at a 1:500 dilution. Samples were incubated with a 1:500 dilution of HPR-conjugated streptavidin. Substrate staining was developed with diaminobenzidine (DAB; Vector Laboratories).

\subsection{Statistical analysis}

Results are shown as mean \pm S. E. Significance of differences between two groups was analysed by unpaired, two-tailed Student's t-test. One-way ANOVA with post hoc Tukey's comparison test was used for comparison among groups. Differences were considered statistically significant at $P \leq 0.05$.

\section{Results}

3.1. ATA enhances VEGF-induced calcineurin signalling in endothelial cells by disrupting the PMCA4/calcineurin interaction

Our previous work demonstrated that PMCA4 negatively modulates VEGF-induced activation of the calcineurin/NFAT signal transduction pathway in endothelial cells [4]. The identification of the small molecule ATA as a PMCA4 inhibitor [26] prompted us to investigate whether ATAmediated PMCA4 inhibition potentiates VEGF-induced calcineurin/ NFAT signalling.

To explore this possibility, primary HUVECs were infected with the NFAT-dependent, luciferase-based adenoviral reporter vector AdNFAT-Luc. Inhibition of PMCA4 is reached at low ATA concentrations in the range of $250 \mathrm{nM}$ [26]. We therefore used this concentration of ATA in our experiments to achieve inhibition of PMCA4 while avoiding inhibitory effects on other cellular proteins that have been shown to require much higher ATA concentrations to be inhibited. Treatment of 
A

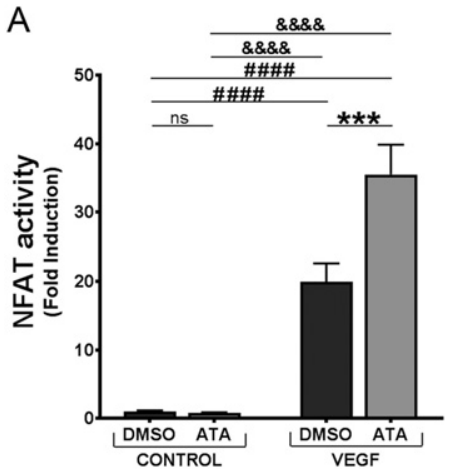

B

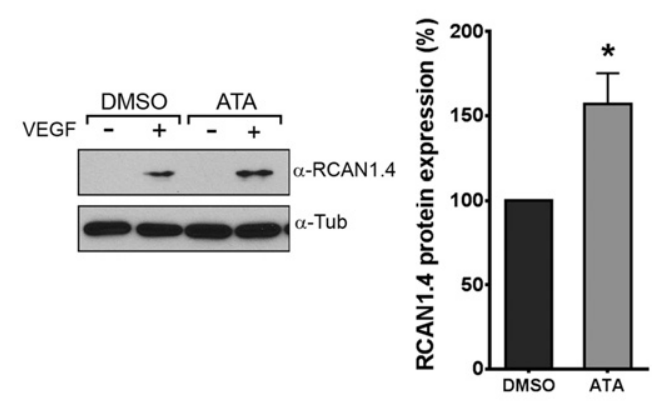

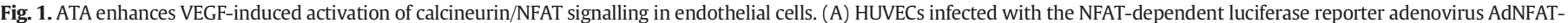

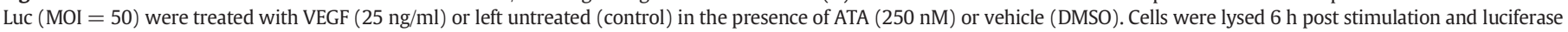

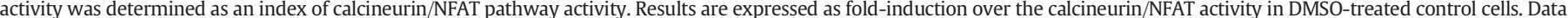

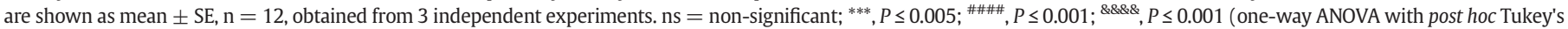

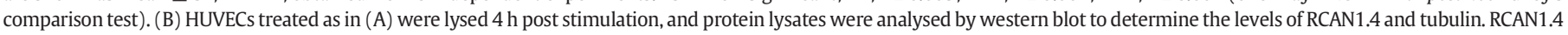

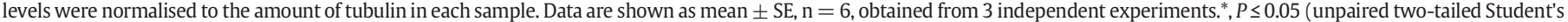
$t$-test) for comparison of cells treated with ATA vs vehicle (DMSO).

Ad-NFAT-Luc-infected HUVECs with 250 nM ATA increased VEGF-induced calcineurin/NFAT pathway activation by $78.1 \%$ (Fig. 1A).

Further analysis on the functional consequences of boosting calcineurin signalling with ATA showed that VEGF-induced protein expression of the NFAT-dependent gene RCAN1.4 was also significantly enhanced (56.8\%) by ATA treatment (Fig. 1B).

These data indicate that ATA potentiates the VEGF-induced activation of the calcineurin/NFAT pathway in endothelial cells, and that this effect is translated into enhanced expression of NFAT-target genes such as RCAN1.4.

PMCA4 is thought to downregulate calcineurin/NFAT pathway activity through a molecular interaction that sequesters calcineurin into low calcium micro-domains created by the pump's calcium extrusion activity [18]. Supporting this idea, disruption of the PMCA4/calcineurin interaction notably potentiates calcineurin/NFAT signalling [4]. We therefore next examined whether the ATA-enhanced calcineurin signalling is associated with changes in the interaction between the two proteins. Membrane-associated proteins were isolated from HUVECs treated with VEGF in the presence or absence of ATA and analysed for the content of PMCA4 and calcineurin. ATA treatment significantly reduced the level of membrane-associated calcineurin, whereas the levels of PMCA4 remain unaffected (Fig. 2A), suggesting that treatment of HUVECs with ATA releases calcineurin from its interaction with PMCA4 in the plasma membrane. Analysis of whole-cell extracts revealed similar levels of calcineurin in control (DMSO) and ATA-treated cells, excluding an effect of ATA on calcineurin expression (Fig. 2B). Total levels of PMCA4 were similarly unaffected in the same samples (Fig. 2B).

To confirm that the decrease in membrane-associated calcineurin was due to disruption of the PMCA4/calcineurin interaction, we performed immunoprecipitation experiments. Protein extracts from HUVECs stimulated with VEGF in the presence or absence of $250 \mathrm{nM}$
A

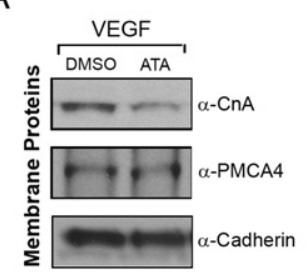

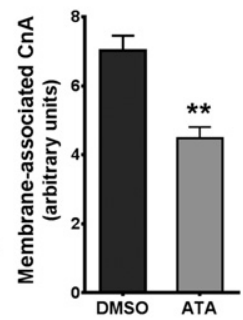

C

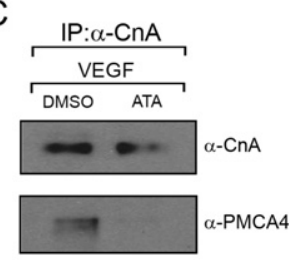

B
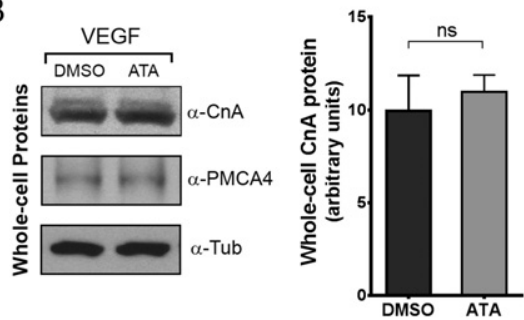

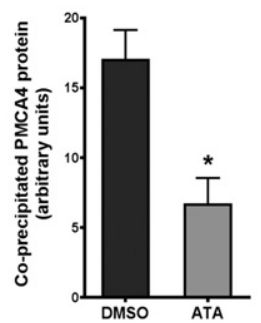

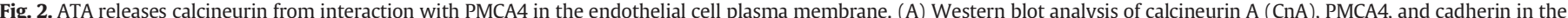

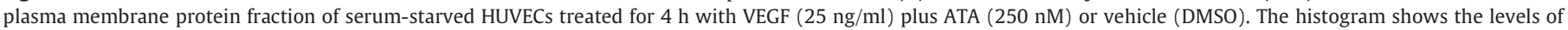

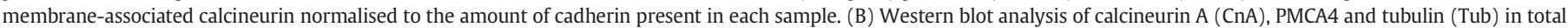

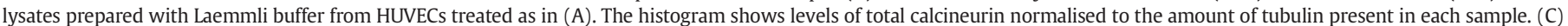

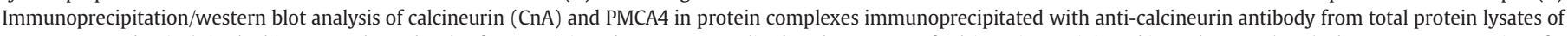

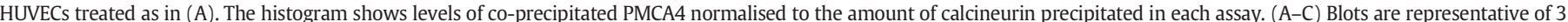

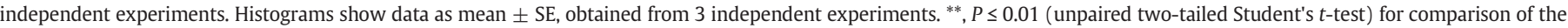

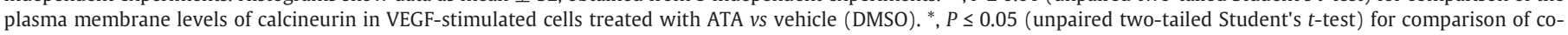
precipitated PMCA4 in VEGF-stimulated HUVECs treated with ATA vs vehicle (DMSO). ns = non-significant. 
ATA were immunoprecipitated with anti-calcineurin antibody. Western blot analysis of the immunoprecipitated proteins revealed that ATA treatment markedly reduced the amount of PMCA4 co-precipitated with calcineurin, suggesting dissociation of the PMCA4/calcineurin complex (Fig. 2C). No significant differences were found in the amount of immunoprecipitated calcineurin in control and ATA-treated cells (Fig. 2C), excluding an effect of ATA on the affinity of the immunoprecipitating antibody for calcineurin.

Together, these data suggest that treatment of endothelial cells with ATA liberates calcineurin from its interaction with PMCA4, thereby potentiating VEGF-mediated activation of calcineurin/NFAT signalling and the subsequent expression of NFAT-target genes such as RCAN1.4.
3.2. ATA increases VEGF-mediated endothelial cell motility and blood vessel formation

PMCA4-mediated inhibition of calcineurin/NFAT signalling negatively regulates endothelial cell migration and tubular morphogenesis [4]. The enhanced calcineurin/NFAT signalling induced by ATA in VEGF-stimulated HUVECs (Fig. 1) suggested that ATA might reverse the negative effect of PMCA4 on these angiogenic processes.

In wound-healing migration assays, exposure of VEGF-stimulated HUVECs to ATA increased cell migration by $58.4 \%$ (Fig. 3A).

To determine whether the ATA-dependent increase in endothelial cell motility involves PMCA4 inhibition, and is not the consequence of
A

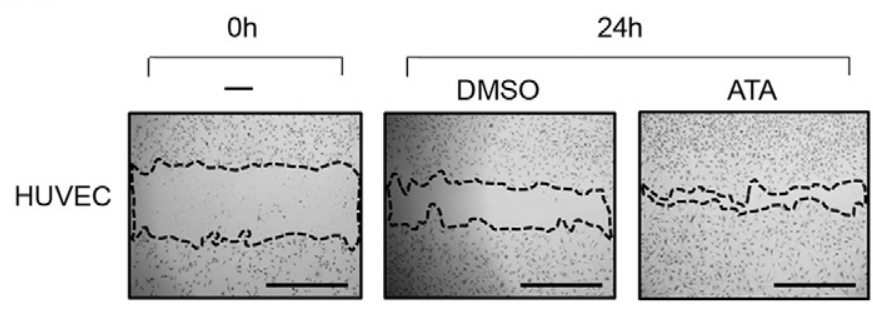

B
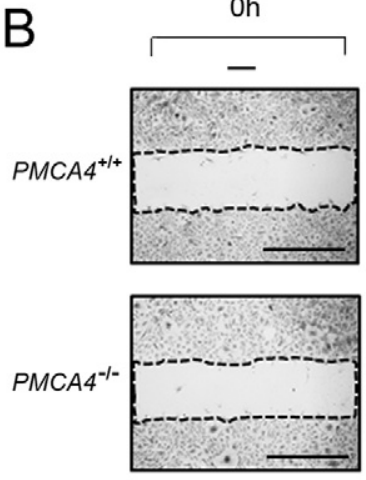

Oh

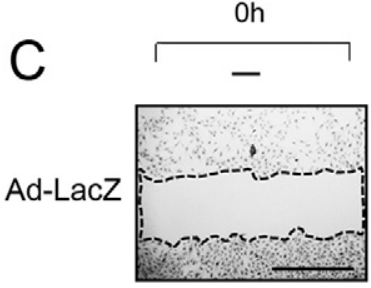

Ad-ID4

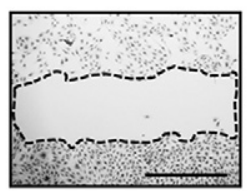

$24 \mathrm{~h}$
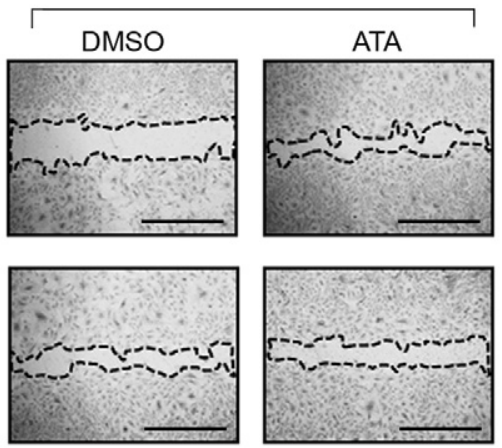

$24 \mathrm{~h}$
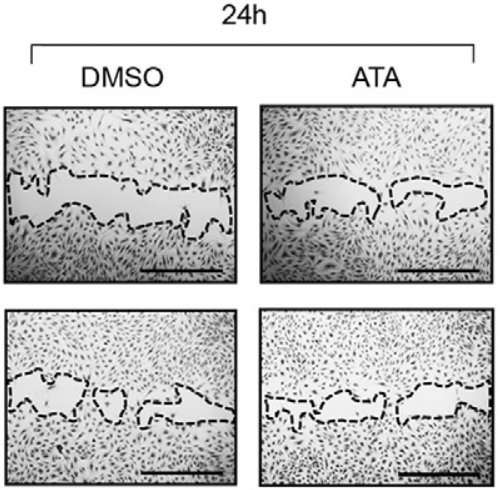
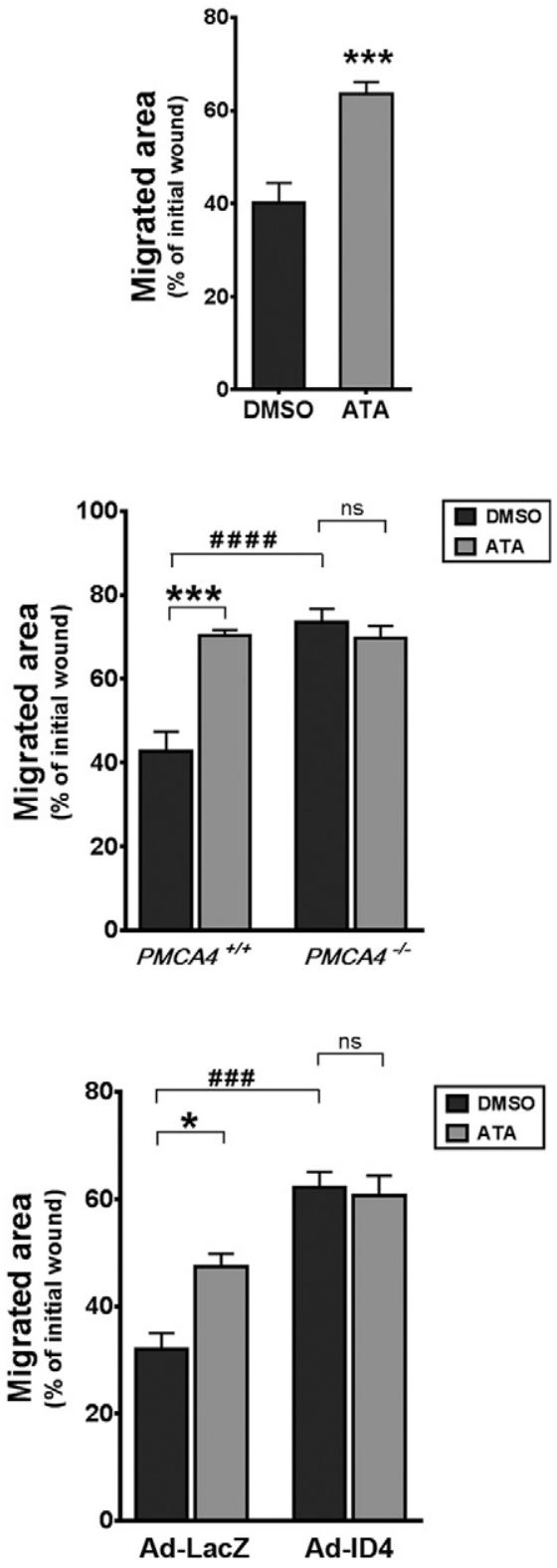

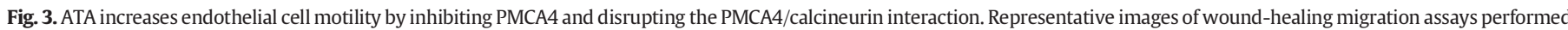

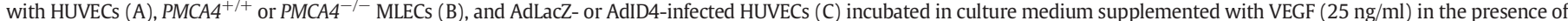

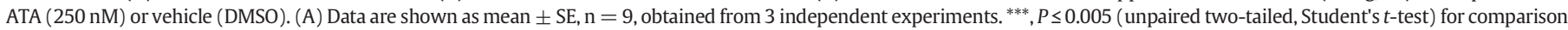

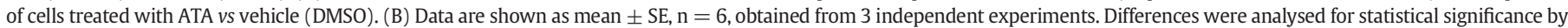

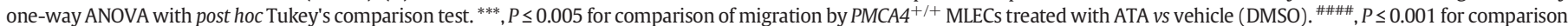

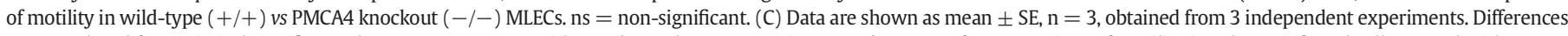

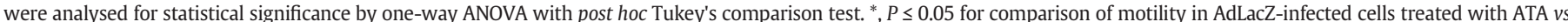

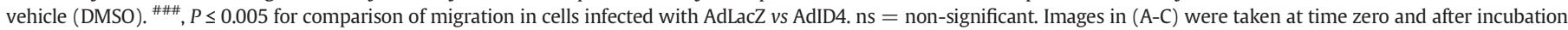

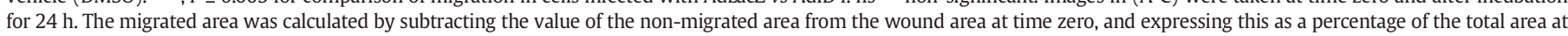
time zero. Scale bars, $1000 \mu \mathrm{m}$. 
off-target effects, migration assays were conducted with mouse lung endothelial cells (MLECs) isolated from $P M C A 4^{-1-}$ knockout mice or their wildtype littermates. Consistent with our published observations [4], PMCA4-deficient cells migrated over longer distances than their wildtype counterparts (Fig. 3B). However, whereas ATA increased wildtype MLEC migration by $64.7 \%$, it had no effect on the migration of PMCA4-deficient MLECs (Fig. 3B).

To investigate whether the ATA-mediated enhanced endothelial cell motility is linked to disruption of the PMCA4/calcineurin interaction, we performed cell migration assays using HUVECs infected with Ad-ID4, an adenoviral vector encoding a PMCA4 region that successfully disrupts association between the two proteins [4]. As a control, HUVECs were infected with an adenovirus encoding $\beta$-Galactosidase (Ad-LacZ). ATA increased the migration of Ad-LacZ-infected cells (Fig. 3C). As we previously reported [4], disruption of the PMCA4/calcineurin interaction in Ad-ID4-infected HUVECs increased cell migration (Fig. 3C), however ATA-treatment did not further increase migration (Fig. 3C). Ad-ID4-infected cells treated with DMSO or ATA expressed equal amounts of ID4, excluding an effect of ATA on adenovirus infection efficiency (Fig. S1). These data not only confirm the implication of PMCA4 in ATA-enhanced endothelial cell migration, but also reveal that disruption of the interaction between PMCA4 and calcineurin is a key molecular mediator of this process.

PMCA4 and the calcineurin/NFAT pathway both have wellestablished roles in the regulation of blood vessel formation $[2,4,14]$. We therefore next investigated the effect of ATA on endothelial cell

A
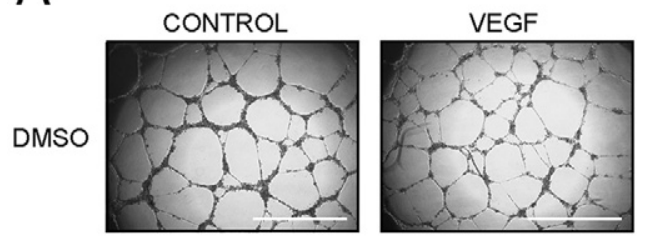

ATA
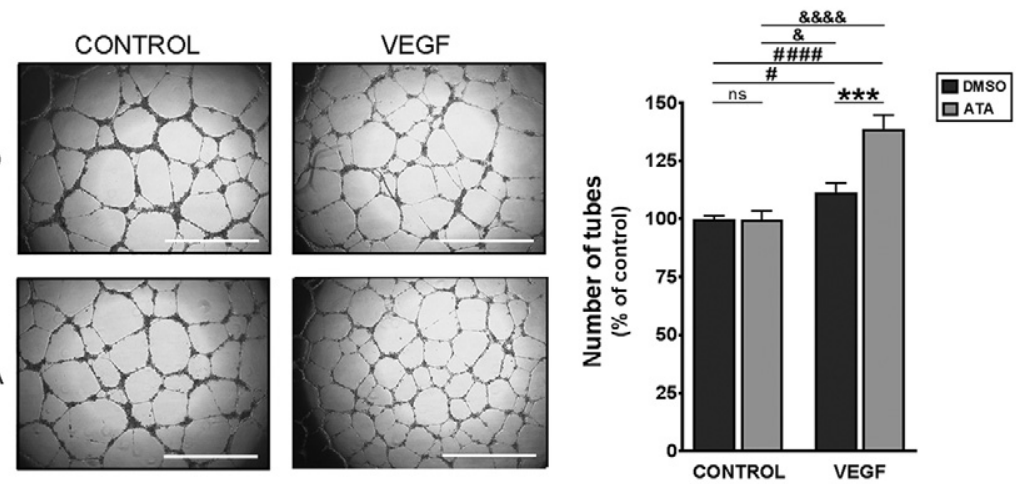

B
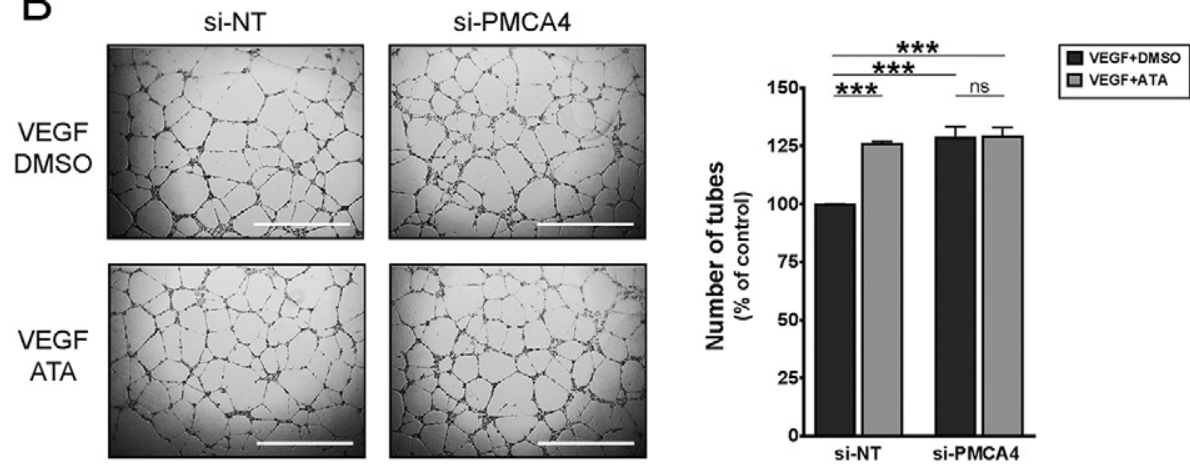

C
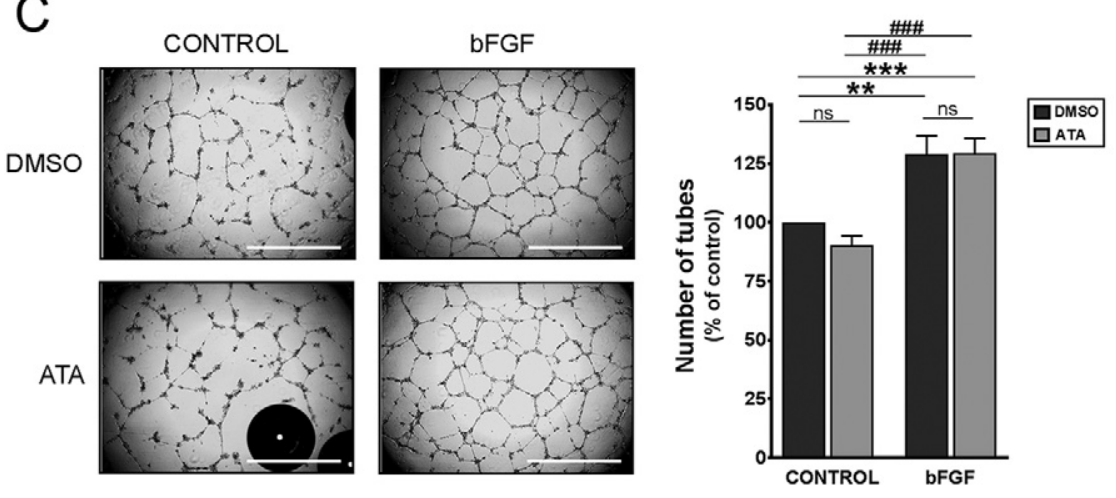

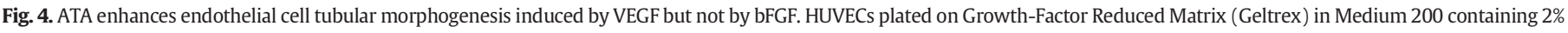

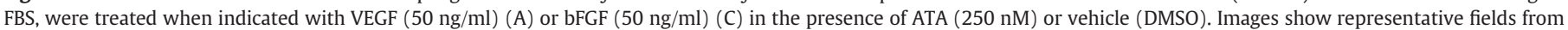

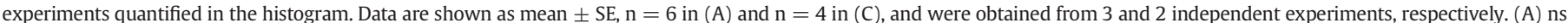

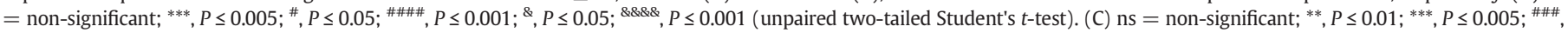

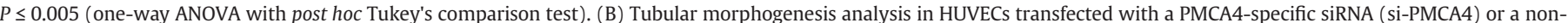

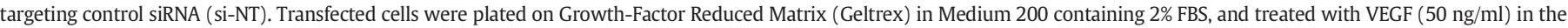

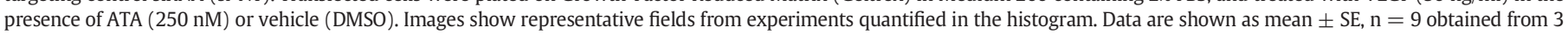
independent experiments. ns = non-significant; ${ }^{* * *}, P \leq 0.005$ (one-way ANOVA with post hoc Tukey's comparison test). (A-C) Scale bars, 1000 m. 
tubular morphogenesis. Consistent with previous studies [4,14], VEGF increased the ability of HUVECs to form capillary-like structures in Matrigel assays (Fig. 4A). VEGF-induced tube formation was further enhanced by co-treatment with ATA (38.9\% increase with respect to control cells) (Fig. 4A). To substantiate the involvement of PMCA4 on the boost in VEGF-induced endothelial cell tubular morphogenesis exerted by ATA, we suppressed PMCA4 expression in endothelial cells using siRNA-mediated technology (Fig. S2). ATA significantly enhanced endothelial cell tubular morphogenesis in VEGF-stimulated cells transfected with a control non-target siRNA (si-NT) (Fig. 4B). As expected, suppression of PMCA4 expression in cells transfected with siRNA targeting PMCA4 (si-PMCA4) increased the ability of the cells to form capillarylike structures in response to VEGF (Fig. 4B), however ATA failed to further increase tubular morphogenesis in these cells (Fig. 4B). This result demonstrates the involvement of PMCA4 in the enhancement of blood vessel formation induced by ATA in endothelial cells stimulated with VEGF.

Interestingly, ATA did not boost tubular morphogenesis in HUVECs stimulated with basic fibroblast growth factor (bFGF), a pro-angiogenic factor that does not activate calcineurin signalling [14] (Fig. 4C).

These observations suggest that inhibition of PMCA4 with ATA markedly enhances VEGF-induced endothelial cell motility and tubular morphogenesis in a calcineurin/NFAT-dependent manner.

Altogether, these results highlight the clinical potential of PMCA4 inhibition and/or disruption of the PMCA4/calcineurin interaction to design novel therapeutic approaches that improve VEGF-induced angiogenesis in patients with cardiovascular ischaemic disease.

\subsection{ATA promotes PMCA4/eNOS interaction and attenuates nitric oxide synthesis in endothelial cells}

Our results in this work establish a major role for the calcineurin/ NFAT signalling pathway in the enhancement of VEGF-induced angiogenesis upon inhibition of PMCA4 with ATA; however, they do not exclude the potential participation of other signalling pathways. In addition to calcineurin, we recently showed that PMCA4 also downregulates the activity of eNOS and the subsequent production of nitric oxide (NO) in endothelial cells [19]. The pro-angiogenic properties of NO are well established [24,45], and VEGF activates eNOS-mediated NO production in endothelial cells [25]. Thus we decided to investigate the effect of ATA on the PMCA4/eNOS interaction, and in the induction of NO synthesis mediated by VEGF in endothelial cells. For this purpose, protein lysates isolated from HUVECs stimulated with VEGF in the presence or absence of $250 \mathrm{nM}$ ATA were immunoprecipitated with the anti-PMCA antibody 5F10. Western blot analysis of immunoprecipitated proteins showed that ATA strongly increased the amount of eNOS co-precipitated with PMCA4 (Fig. 5A). No significant differences were observed in the amount of PMCA4 precipitated in control or ATA-treated cells (Fig. 5A) ruling out an effect of ATA on the affinity of the immunoprecipitating antibody for PMCA4. This result indicates that ATA promotes the association between PMCA4 and eNOS. Accordingly, functional experiments in HUVECs showed that ATA (250 nM) significantly attenuate NO synthesis in VEGF-stimulated cells (Fig. 5B), excluding NO as an effector of the enhancement in angiogenesis mediated by ATA.

\subsection{Low ATA levels are not toxic to endothelial cells}

Our observations suggest that inhibition of PMCA4 with ATA has therapeutic potential for the promotion of blood vessel formation in situations characterized by insufficient angiogenesis. To evaluate this possibility we first monitored for any effect of ATA on endothelial cell viability. Exposure of HUVECs to $250 \mathrm{nM}$ ATA did not affect proliferation or cell viability (Fig. 6A), and also had no effect on the VEGF-induced phosphorylation (activation) status of Erk1/2 (Fig. 6B), indicating that
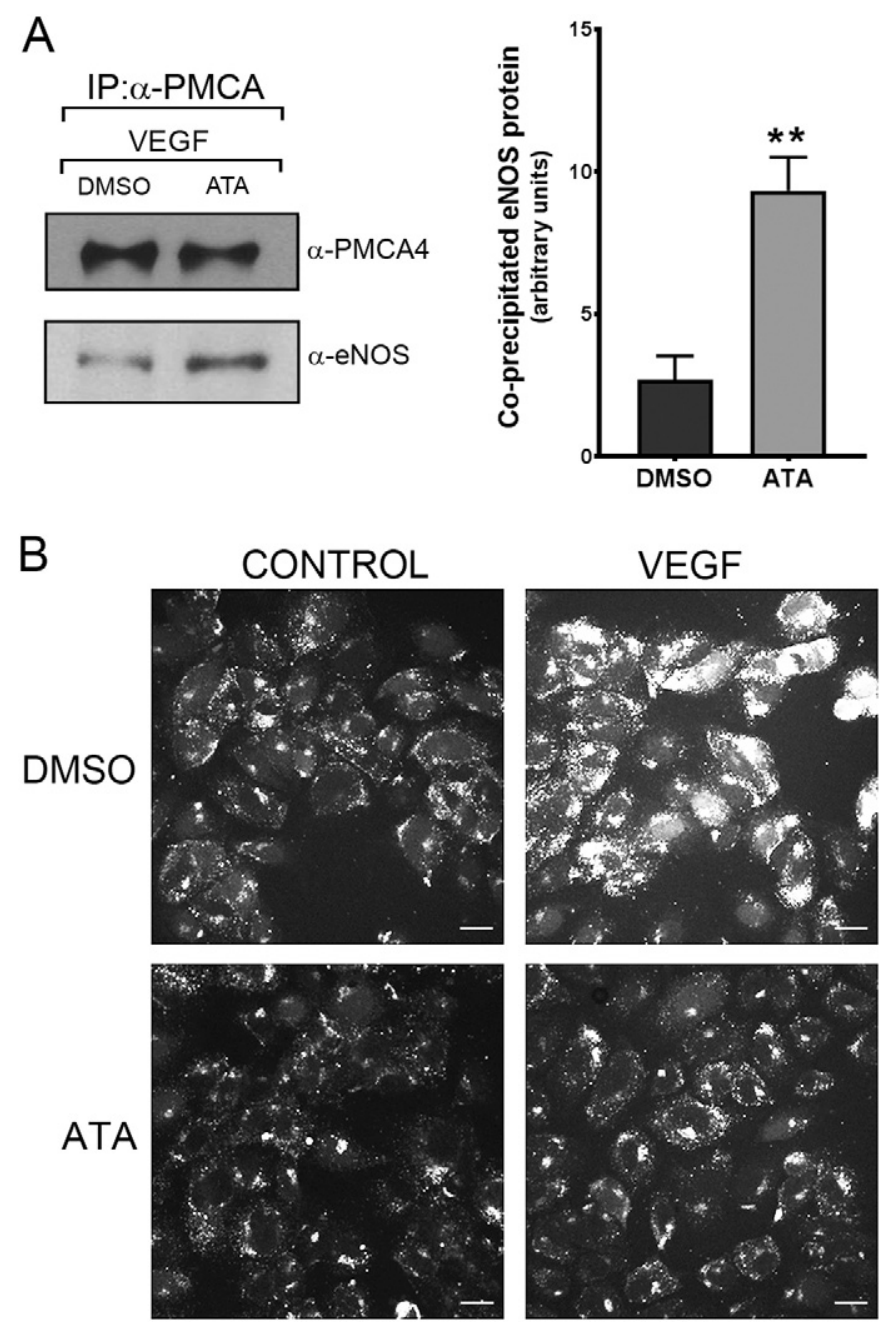

Fig. 5. ATA treatment potentiates the PMCA4/eNOS interaction and attenuates nitric oxide synthesis in endothelial cells stimulated with VEGF. (A) Serum-starved HUVECs were treated with VEGF $(25 \mathrm{ng} / \mathrm{ml})$ and ATA ( $250 \mathrm{nM}$ ) or vehicle (DMSO) for $5 \mathrm{~min}$. Protein lysates were immunoprecipitated with the anti-PMCA 5F10 monoclonal antibody, and levels of PMCA4 and eNOS in the immunoprecipitated proteins analysed by western blot. Histogram shows levels of co-precipitated eNOS normalised to the amount of PMCA4 precipitated in each assay. Data are shown as mean \pm SE obtained from 3 independent experiments. ${ }^{* *}$ indicates statistically significant differences $(P \leq 0.01$ according to unpaired, two-tailed Student's $t$-test) in the levels of eNOS co-precipitated in samples treated with ATA vs DMSO. Western blot images are representative of 3 independent immunoprecipitation experiments. (B) HUVECs were treated as indicated in (A). Intracellular levels of nitric oxide were determined by staining cells with the NOsensitive dye DAF-FM. Images showing microscopy fields of DAF-FM staining in cells are representative of 2 independent experiments. Scale bars, $20 \mu \mathrm{m}$.

low ATA concentrations do not modify the activity of this proliferative signal transduction pathway.

In contrast, long-term exposure of HUVECs to a higher concentration $(20 \mu \mathrm{M})$ reduced cell viability (Fig. S3A) and abolished the ability of VEGF-stimulated HUVECs to form capillary-like structures in matrigel assays (Fig. S3B). To investigate the reasons underlying the toxic effects of high concentrations of ATA on endothelial cells, we first determined whether micromolar concentrations of ATA might induce any changes in the $\mathrm{pH}$ of the culture medium. Analysis of cultures of HUVECs incubated in medium containing vehicle (DMSO), or ATA at low $(0.25 \mu \mathrm{M})$ or high $(20 \mu \mathrm{M})$ concentration for different periods showed no differences in the $\mathrm{pH}$ of the medium (Fig. S3C). Another possibility to explain the harmful effect of $20 \mu \mathrm{M}$ ATA on the viability of endothelial cells could be that high ATA concentrations in the culture medium might result in deleterious osmotic stress on the cells. To test this possibility we checked the activation of ATF-2, a transcription factor well-known to 
A

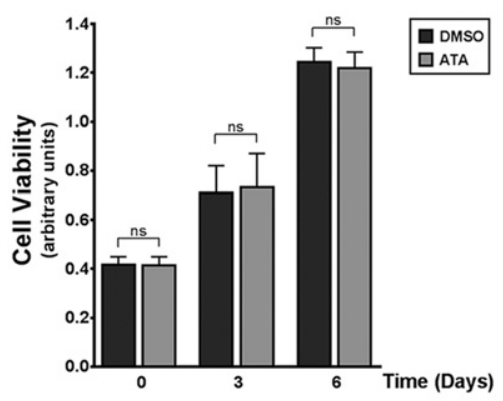

B

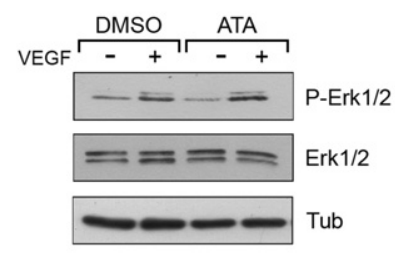

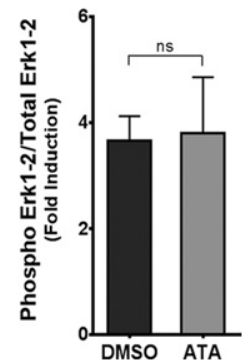

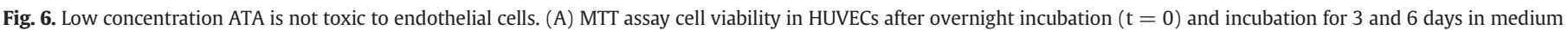

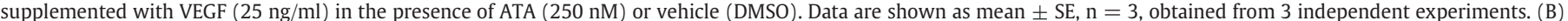

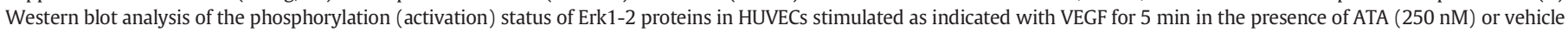

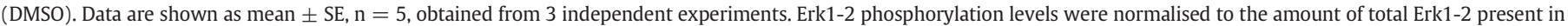
each sample. Data are expressed as the fold-induction in Erk1-2 phosphorylation relative to the value in unstimulated cells. ns = non-significant.

respond to osmotic stress [29,39], in HUVECs grown in tissue culture medium containing low or high concentrations of ATA. No changes in the phosphorylation (activation) status of ATF-2 were detected in cells grown in medium containing $20 \mu \mathrm{M}$ ATA compared to cells grown in $0.25 \mu \mathrm{M}$ ATA or vehicle (DMSO) (Fig. S3D). Osmotic stress induced by high concentration of $\mathrm{NaCl}$ in the medium resulted in ATF-2 phosphorylation confirming the suitably of the assay (Fig. S3D).

To analyse potential toxic effects of ATA in a more physiological setting, we treated zebrafish embryos with increasing ATA concentrations. Consistent with the in vitro data, low ATA concentrations $(50-100 \mu \mathrm{M})$ caused no significant damage to embryos, which developed a normal vascular anatomy (Fig. S4). In contrast, exposure to ATA concentrations above $100 \mu \mathrm{M}$ was associated with embryo death (Fig. S4).

Although our results demonstrate proof-of-concept for pharmacological targeting of PMCA4 in therapeutic approaches, refined versions of ATA with high specificity for PMCA4 will be required to design efficient and safe clinical interventions.

\subsection{ATA enhances post-ischaemic hindlimb perfusion in vivo}

To evaluate in vivo the therapeutic potential of PMCA4 inhibition to promote reperfusion of ischaemic tissues, we used the mouse hindlimb ischaemia model. We have used two surgical approaches to induce different levels of ischaemia in the lower limb of mice [8,21]. In a first approach, limb ischaemia was induced by proximal and distal ligation of a short fragment of the femoral artery with excision of the intervening segment. This procedure induces limb ischaemia by significantly reducing the flow of blood to the limb but still maintains a low degree of blood flow to the muscle. Initially we chose this model to maintain a low degree of blood flow that could mediate the delivery of ATA to the ischaemic organ. To evaluate the effect of ATA on this setting, vehicle (DMSO) or ATA was administered intraperitoneally $2 \mathrm{~h}$ after surgery and daily for 3 more days. Given the harmful effects of high ATA concentrations (Fig. S3 and S4) we selected a dose of $5 \mathrm{mg} / \mathrm{kg} /$ day, which is not associated with damage in mice [27]. Laser Doppler imaging analysis of blood flow performed 4 days after surgery revealed a significant increase in the reperfusion of post-ischaemic limbs treated with ATA (Fig. 7). To explore whether ATA would be able to exert the same effect in a model of deep acute ischaemia, in a separate set of experiments we performed femoral ligation and excision of the intervening segment but on this occasion we ligated and excised a longer femoral segment. This procedure totally blunted blood flow to the lower limb (Fig. S5A). As expected, loss of blood flow resulted in a strong upregulation of VEGF expression in the ischaemic limb (Fig. S6). Blood flow to the ischaemic limb was progressively recovered along time (Fig. S5A). In concurrence with our initial data, administration of ATA to these animals also enhanced significant reperfusion of the ischaemic limb (Fig. S5A-B) although, in this case, administration of ATA for 7-10 days was required to detect the enhancement of blood flow mediated by the drug. It is likely that in this model, a longer period of ATA administration is required because ATA delivery to the ischaemic area is compromised during the first days post-surgery due to the absence of blood flow.
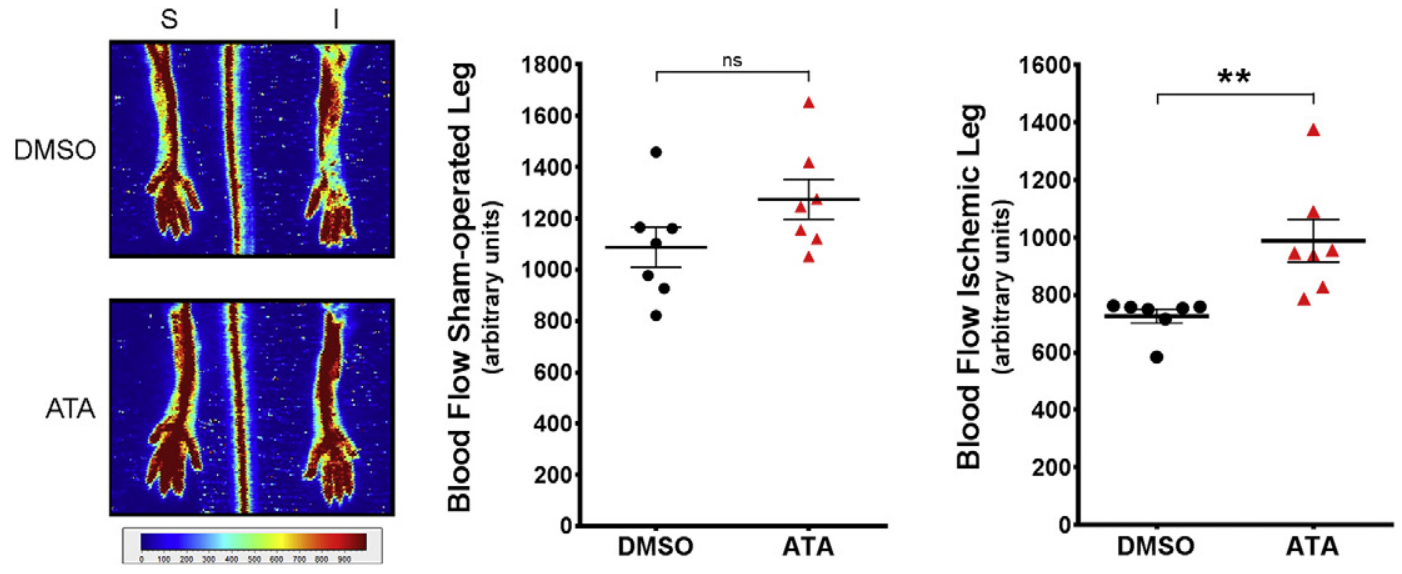

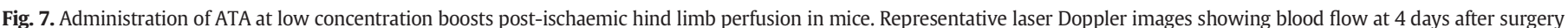

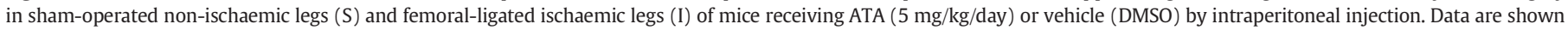

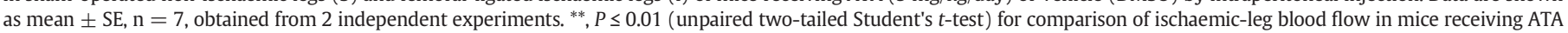
$v s$ vehicle. $\mathrm{ns}=$ non-significant. 
These data obtained using in vivo animal models reinforce the therapeutic potential of pharmacological targeting of PMCA4 to promote tissue reperfusion in patients with ischaemic cardiovascular disease.

\section{Discussion}

In this study, we demonstrate that inhibition of the plasma membrane calcium ATPase 4 (PMCA4) with low concentrations of the small polyaromatic compound aurintricarboxylic acid (ATA) significantly enhances VEGF-induced angiogenic processes. Our results show proof-of-concept for targeting PMCA4 therapeutically to improve VEGF-based pro-angiogenic interventions in patients with ischaemic cardiovascular disease. In this work we have used ATA to inhibit the function of PMCA4. The feasibility of ATA as a clinical treatment has yet to be tested, but pre-clinical studies in animal models have revealed potential clinical applications in the treatment of cardiac hypertrophy [27], experimental autoimmune encephalomyelitis [43], sepsis [22], and myocardial ischaemia-reperfusion injury [44].

Our results show that high levels of ATA strongly reduce endothelial cell viability and abolish tube formation. Consistent with our results, Lipo et al. [23] reported that increasing ATA concentrations diminish the ability of endothelial cells to form tubular-like structures in matrigel assays. Furthermore, in the same study, the authors report that intravitreal injection of $1.5 \mu \mathrm{g}$ ATA in $2 \mu \mathrm{l} 10 \%$ DMSO (corresponding to $1.78 \mathrm{mM}$ ATA) into mice strongly attenuates laser-induced choroidal neovascularization. It is highly likely that the reduced ocular vascularization observed by Lipo et al. [23] results from the toxicity associated with high ATA concentrations, an interpretation supported by our experiments in zebrafish embryos (Fig. S4) and those reported by Smee et al. [36] in mice. Furthermore, 5-20 $\mu \mathrm{M}$ ATA has been shown to reduce the growth rate of fibroblasts [5] and smooth muscle cells [6]. In this work we have not identified the mechanisms underlying the harmful effect on endothelial cell viability exerted by high levels of ATA but, at these concentrations, ATA has been reported to non-specifically inhibit the action of nucleases [13], calpain [32] and several chemokine receptors [43], suggesting possible explanations for the toxicity of high-concentration ATA. The deleterious effects exerted by ATA at high concentrations indicate that refined, highly selective versions of this molecule will be required for efficient therapeutic interventions to treat patients with chronic ischaemic disease without associated harmful side-effects.

Mechanistically, ATA enhances VEGF-induced activation of the calcineurin/NFAT pathway in endothelial cells, in turn boosting calcineurin-dependent angiogenic processes such as endothelial cell migration and tubular morphogenesis. Our data indicate that ATA increases calcineurin signalling by disrupting its interaction with calcineurin at the plasma membrane. At present, we do not know the molecular process by which ATA disrupts the PMCA4/calcineurin complex. A possible explanation is masking by ATA of the calcineurininteracting region in PMCA4 (amino acids 428 to 651 in human PMCA4b) [9]. Supporting this possibility, ATA inhibits hepatitis C helicase by a similar mechanism, binding to a defined region in the enzyme and thereby blocking interaction with nucleic acids [35]. However, a different picture emerges from analysis of the effect of ATA on PMCA4 binding to endothelial nitric oxide synthase (eNOS), which interacts with the same PMCA4 domain as calcineurin [19]. Rather than decreasing the interaction, ATA promotes association between PMCA4 and eNOS (Fig. 5A). The opposite effects of ATA on PMCA4 binding to calcineurin or eNOS suggests that ATA is unlikely to be an allosteric competitor with partner proteins for binding to the 428-651 PMCA4 domain. It will be interesting in future research to fully define the molecular events implicated in ATA-mediated disruption of PMCA4/calcineurin interaction and the differential effect of ATA on PMCA4 binding to calcineurin or eNOS.

The results presented here establish a key role for the calcineurin/ NFAT signalling pathway in the enhancement of VEGF-induced angiogenesis upon inhibition of PMCA4 with low ATA concentrations. We have previously reported that PMCA4 also downregulates eNOS activity and NO production in endothelial cells [19]. Here, we show that ATA attenuates VEGF-induced nitric oxide production in endothelial cells, suggesting that NO signalling is not implicated in the enhancement of angiogenesis mediated by ATA; however, our results do not exclude the potential participation of other signalling pathways. Further investigations into the molecular mechanisms underlying ATA-mediated enhancement of VEGF signalling promise to reveal novel molecular targets for improving pro-angiogenic therapy.

Our in vivo experiments in animal models of experimentally induced hindlimb ischaemia show that ATA enhances reperfusion of post-ischaemic limbs. Given that our experiments using HUVECs in culture have shown that ATA markedly enhances VEGF-induced angiogenesis in vitro, it is likely that the increase in reperfusion of post-ischaemic limbs induced by ATA involves increased revascularisation of the muscle, although a full characterization of the effect of ATA on angiogenesis in vivo will require further investigations.

The present study indicates that targeting PMCA4 could improve VEGF-based pro-angiogenic interventions, highlighting the clinical potential of using PMCA4 inhibitors for the treatment of ischaemic cardiovascular disease. Interestingly, in addition to the ATA-mediated increase in reperfusion of ischaemic limbs, a trend to increase blood flow in nonischaemic (sham-operated) muscle was also observed in the animals treated with ATA (Fig. 7 and S5) although these differences did not reach statistical significance $(P=0.0558)$. Our findings in cultured HUVECs have shown that ATA enhances blood vessel formation in the presence of VEGF but does not have any effect when it is added to serum-starved cells (Fig. 4). We speculate that the increased blood flow in non-ischaemic limbs of animals treated with ATA might be the result of ATA acting in conjunction with low physiological levels of VEGF normally present in the muscle (Fig. S6). We think this is extremely interesting from a therapeutic point of view, as one of the main obstacles for success of current VEGF-based therapeutic strategies is the difficulty to achieve high ectopic expression of VEGF in the ischaemic organ [42]. In fact, although it is thought that VEGF-based gene therapy is the best way forward in future therapeutic approaches, adenoviral vectors only transduce a small percentage of the target cells in humans [41]. Thus, selective PMCA4 inhibitors might be useful co-adjuvants in VEGF-based gene therapy strategies to enhance reperfusion of ischaemic tissues even in situations where expression of ectopic VEGF is not very high. Our in vivo data in this work do not allow evaluating the efficiency of single versus combined ATA/VEGF therapies. Further studies are required to analyse the pharmacokinetics of single and combined ATA/VEGF therapies in preclinical animal models of cardiovascular ischaemic disease.

\section{Funding}

This work was supported by the Research Institute in Healthcare Sciences, Faculty of Science and Engineering, University of Wolverhampton (to A.L.A.), and by an MRC programme grant (grant G1002082 to L.N. and E.J.C.).J.M.R. is supported by the Spanish Ministry of Economy, Industry and Competitiveness (MEIC) (grant SAF2015-636333 to J.M.R.) and CIBERCV of Ministerio de Sanidad (grant CB16/11/00264 to J.M.R.), all projects cofounded by FEDER. J.M.R. and J.F.N. are supported by Red de Investigación Cardiovascular (RD12/0042/0018 and 0022) cofounded by FEDER. S.K. and A.L.A. are supported by the Rosetrees Trust (grant M531 to A.L.A). S.M-M. and J.M.R. are supported by grants from the Fundacion La Marato TV3 (grant 20122532 to S.M-M. and grant 20151331 to J.M.R.). The Centro Nacional de Investigaciones Cardiovasculares (CNIC) is supported by the Spanish Ministry of Economy, Industry and Competitiveness (MEIC) and the Pro-CNIC Foundation, and is a Severo Ochoa Center of Excellence (Award SEV-2015-0505). 


\section{Conflict of interest}

None declared.

\section{Acknowledgments}

We thank Simon Bartlett for English editing and Alicia Peral for technical assistance.

\section{Appendix A. Supplementary data}

Supplementary data to this article can be found online at http://dx. doi.org/10.1016/j.yjmcc.2017.07.001.

\section{References}

[1] H. Al Sabti, Therapeutic angiogenesis in cardiovascular disease, J. Cardiothorac. Surg. 2 (2007) 49-55.

[2] A.L. Armesilla, E. Lorenzo, P. Gómez del Arco, S. Martínez-Martínez, A. Alfranca, J.M Redondo, Vascular endothelial growth factor activates nuclear factor of activated T cells in human endothelial cells: a role for tissue factor gene expression, Mol. Cell. Biol. 19 (1999) 2032-2043.

[3] R.R. Baggott, T.M. Mohamed, D. Oceandy, M. Holton, M.C. Blanc, S.C. Roux-Soro, S. Brown, J.E. Brown, E.J. Cartwright, W. Wang, L. Neyses, A.L. Armesilla, Disruption of the interaction between PMCA2 and calcineurin triggers apoptosis and enhances paclitaxel-induced cytotoxicity in breast cancer cells, Carcinogenesis 33 (2012) 2362-2368.

[4] R.R. Baggott, A. Alfranca, D. López-Maderuelo, T.M. Mohamed, A. Escolano, J. Oller, B.C. Ornes, S. Kurusamy, F.B. Rowther, J.E. Brown, D. Oceandy, E.J. Cartwright, W. Wang, P. Gómez-del Arco, S. Martínez-Martínez, L. Neyses, J.M. Redondo, A.L Armesilla, Plasma membrane calcium ATPase isoform 4 inhibits vascular endothelial growth factor-mediated angiogenesis through interaction with calcineurin, Arterioscler. Thromb. Vasc. Biol. 34 (2014) 2310-2320.

[5] M. Benezra, I. Vlodavsky, A. Yayon, R. Bar-Shavit, J. Regan, M. Chang, S. Ben-Sasson, Reversal of basic fibroblast growth factor-mediated autocrine cell transformation by aromatic anionic compounds, Cancer Res. 52 (1992) 5656-5662.

[6] M. Benezra, S.A. Ben-Sasson, J. Regan, M. Chang, R. Bar-Shavit, I. Vlodavsky, Antiproliferative activity to vascular smooth muscle cells and receptor binding of heparinmimicking polyaromatic anionic compounds, Arterioscler. Thromb. Vasc. Biol. 14 (1994) 1992-1999.

[7] Y. Blum, H.G. Belting, E. Ellertsdottir, L. Herwig, F. Lüders, M. Affolter, Complex cell rearrangements during intersegmental vessel sprouting and vessel fusion in the zebrafish embryo, Dev. Biol. 316 (2008) 312-322.

[8] R.A. Brenes, C.C. Jadlowiec, M. Bear, P. Hashim, C.D. Protack, X. Li, W. Lv, M.J. Collins, A. Dardik, Toward a mouse model of hind limb ischemia to test therapeutic angiogenesis, J. Vasc. Surg. 56 (6) (2012 Dec) 1669-1679.

[9] M.H. Buch, A. Pickard, A. Rodriguez, S. Gillies, A.H. Maass, M. Emerson, E.J. Cartwright, J.C. Williams, D. Oceandy, J.M. Redondo, L. Neyses, A.L. Armesilla, The sarcolemmal calcium pump inhibits the calcineurin/nuclear factor of activated Tcell pathway via interaction with the calcineurin A catalytic subunit, J. Biol. Chem. 280 (2005) 29479-29487.

[10] P. Carmelit, R.K. Jain, Molecular mechanisms and clinical applications of angiogenesis, Nature 473 (2011) 298-307.

[11] J.P. Cooke, D.W. Losordo, Modulating the vascular response to limb ischemia: angiogenic and cell therapies, Circ. Res. 116 (2015) 1561-1578.

[12] R. Gupta, J. Tongers, D.W. Losordo, Human studies of angiogenic gene therapy, Circ. Res. 105 (2009) 724-736.

[13] R.B. Hallick, B.K. Chelm, P.W. Gray, E.M. Orozco Jr., Use of aurintricarboxylic acid as an inhibitor of nucleases during nucleic acid isolation, Nucleic Acids Res. 4 (1977) 3055-3064.

[14] G.L. Hernández, O.V. Volpert, M.A. Iñiguez, E. Lorenzo, S. Martínez-Martínez, R. Grau, M. Fresno, J.M. Redondo, Selective inhibition of vascular endothelial growth factormediated angiogenesis by cyclosporin A: roles of the nuclear factor of activated $\mathrm{T}$ cells and cyclooxygenase 2, J. Exp. Med. 193 (2001) 607-620.

[15] P.G. Hogan, L. Chen, J. Nardone, A. Rao, Transcriptional regulation by calcium, calcineurin, and NFAT, Genes Dev. 17 (2003) 2205-2232.

[16] B.M. Hogan, F.L. Bos, J. Bussmann, M. Witte, N.C. Chi, H.J. Duckers, S. Schulte-Merker, Ccbe1 is required for embryonic lymphangiogenesis and venous sprouting, Nat. Genet. 41 (2009) 396-398.

[17] M. Holton, D. Yang, W. Wang, T.M. Mohamed, L. Neyses, A.L. Armesilla, The interaction between endogenous calcineurin and the plasma membrane calcium-dependent ATPase is isoform specific in breast cancer cells, FEBS Lett. 581 (2007) 4115-4119.

[18] M.L. Holton, W. Wang, M. Emerson, L. Neyses, A.L. Armesilla, Plasma membrane calcium ATPase proteins as novel regulators of signal transduction pathways, World J. Biol. Chem. 1 (2010) 201-208.

[19] M. Holton, T.M. Mohamed, D. Oceandy, W. Wang, S. Lamas, M. Emerson, L. Neyses, A.L. Armesilla, Endothelial nitric oxide synthase activity is inhibited by the plasm membrane calcium ATPase in human endothelial cells, Cardiovasc. Res. 87 (2010) 440-448.
[20] C.B. Klee, H. Ren, X. Wang, Regulation of the calmodulin-stimulated protein phosphatase, calcineurin, J. Biol. Chem. 273 (1998) 13367-13370.

[21] S.M. Krishna, S.M. Omer, J. Golledge, Evaluation of the clinical relevance and limitations of current pre-clinical models of peripheral artery disease, Clin. Sci. (Lond.) 130 (2016) 127-150.

[22] L.J. Laufenberg, A.A. Kazi, C.H. Lang, Salutary effect of aurintricarboxylic acid on endotoxin- and sepsis-induced changes in muscle protein synthesis and inflammation, Shock 41 (2014) 420-428.

[23] E. Lipo, S.M. Cashman, R. Kumar-Singh, Aurintricarboxylic acid inhibits complement activation, membrane attack complex, and choroidal neovascularization in a model of macular degeneration, Invest. Ophthalmol. Vis. Sci. 54 (2013) 7107-7114.

[24] D. Luque Contreras, H. Vargas Robles, E. Romo, A. Rios, B. Escalante, The role of nitric oxide in the post-ischemic revascularization process, Pharmacol. Ther. 112 (2006) 553-563.

[25] B.J. Michell, J.E. Griffiths, K.I. Mitchelhill, I. Rodriguez-Crespo, T. Tiganis, S. Bozinovski, P.R. de Montellano, B.E. Kemp, R.B. Pearson, The Akt kinase signals directly to endothelial nitric oxide synthase, Curr. Biol. 9 (1999) 845-848.

[26] T.M. Mohamed, R. Abou-Leisa, F. Baudoin, N. Stafford, L. Neyses, E.J. Cartwright, D. Oceandy, Development and characterization of a novel fluorescent indicator protein PMCA4-GCaMP2 in cardiomyocytes, J. Mol. Cell. Cardiol. 63 (2013) 57-68.

[27] T.M. Mohamed, R. Abou-Leisa, N. Stafford, A. Maqsood, M. Zi, S. Prehar, F. BaudoinStanley, X. Wang, L. Neyses, E.J. Cartwright, D. Oceandy, The plasma membrane calcium ATPase 4 signalling in cardiac fibroblasts mediates cardiomyocyte hypertrophy, Nat. Commun. 7 (2016) 11074-11090.

[28] D. Mozaffarian, E.J. Benjamin, A.S. Go, D.K. Arnett, M.J. Blaha, M. Cushman, S. de Ferranti, J.P. Després, H.J. Fullerton, V.J. Howard, M.D. Huffman, S.E. Judd, B.M. Kissela, D.T. Lackland, J.H. Lichtman, L.D. Lisabeth, S. Liu, R.H. Mackey, D.B. Matchar, D.K. McGuire, E.R. Mohler 3rd, C.S. Moy, P. Muntner, M.E. Mussolino, K. Nasir, R.W. Neumar, G. Nichol, L. Palaniappan, D.K. Pandey, M.J. Reeves, C.J. Rodriguez, P.D. Sorlie, J. Stein, A. Towfighi, T.N. Turan, S.S. Virani, J.Z. Willey, D. Woo, R.W. Yeh, M.B. Turner, American Heart Association statistics committee and stroke statistics subcommittee, Circulation 131 (2015) e29-e322.

[29] D.M. Ouwens, N.D. de Ruiter, G.C. van der Zon, A.P. Carter, J. Schouten, C. van der Burgt, K. Kooistra, J.L. Bos, J.A. Maassen, H. van Dam, Growth factors can activate ATF2 via a two-step mechanism: phosphorylation of Thr71 through the Ras-MEKERK pathway and of Thr69 through RalGDS-Src-p38, EMBO J. 21 (2002) 3782-3793.

[30] K. Pászty, A.J. Caride, Ž. Bajzer, C.P. Offord, R. Padányi, L. Hegedűs, K. Varga, E.E. Strehler, A. Enyedi, Plasma membrane $\mathrm{Ca}^{2+}$-ATPases can shape the pattern of $\mathrm{Ca}^{2+}$ transients induced by store-operated $\mathrm{Ca}^{2+}$ entry, Sci. Signal. 8 (2015) ra19.

[31] J.A. Plumb, R. Milroy, S.B. Kaye, Effects of the pH dependence of 3-(4,5-dimethylthiazol-2-yl)-2,5-diphenyl-tetrazolium bromide-formazan absorption on chemosensitivity determined by a novel tetrazolium-based assay, Cancer Res. 49 (1989) 4435-4440.

[32] A. Posner, K.J. Raser, I. Hajimohammadreza, P.W. Yuen, K.K. Wang, Aurintricarboxylic acid is an inhibitor of mu- and m-calpain, Biochem. Mol. Biol. Int. 36 (1995) 291-299.

[33] T. Sachs, F. Pomposelli, A. Hamdan, M. Wyers, M. Schermerhorn, Trends in the national outcomes and costs for claudication and limb threatening ischemia: angioplasty vs bypass graft, J. Vasc. Surg. 54 (2011) 1021-1031.

[34] K. Schuh, EJ. Cartwright, E. Jankevics, K. Bundschu, J. Liebermann, J.C. Williams, A.L. Armesilla, M. Emerson, D. Oceandy, K.P. Knobeloch, L. Neyses, Plasma membrane $\mathrm{Ca} 2+$ ATPase 4 is required for sperm motility and male fertility, J. Biol. Chem. 279 (2004) 28220-28226.

[35] W.R. Shadrick, S. Mukherjee, A.M. Hanson, N.L. Sweeney, D.N. Frick, Aurintricarboxylic acid modulates the affinity of hepatitis C virus NS3 helicase for both nucleic acid and ATP, Biochemistry 52 (2013) 6151-6159.

[36] D.F. Smee, B.L. Hurst, M.H. Wong, Lack of efficacy of aurintricarboxylic acid and ethacrynic acid against vaccinia virus respiratory infections in mice, Antivir. Chem. Chemother. 20 (2010) 201-205.

[37] E.E. Strehler, A.J. Caride, A.G. Filoteo, Y. Xiong, J.T. Penniston, A. Enyedi, Plasma membrane $\mathrm{Ca} 2$ + ATPases as dynamic regulators of cellular calcium handling, Ann. N. Y. Acad. Sci. 1099 (2007) 226-236.

[38] H. Takahashi, M. Shibuya, The vascular endothelial growth factor (VEGF)/VEGF receptor system and its role under physiological and pathological conditions, Clin. Sci. (Lond.) 109 (2005) 227-241.

[39] L. Wang, R. Payton, W. Dai, L. Lu, Hyperosmotic stress-induced ATF-2 activation through Polo-like kinase 3 in human corneal epithelial cells, J. Biol. Chem. 286 (2011) 1951-1958.

[40] S. Ylä-Herttuala, Cardiovascular gene therapy with vascular endothelial growth factors, Gene 525 (2013) 217-219.

[41] S. Ylä-Herttuala, K. Alitalo, Gene transfer as a tool to induce therapeutic vascular growth, Nat. Med. 9 (2003) 694-701.

[42] I. Zachary, R.D. Morgan, Therapeutic angiogenesis for cardiovascular disease: biological context, challenges, prospects, Heart 97 (2011) 181-189.

[43] F. Zhang, W. Wei, H. Chai, X. Xie, Aurintricarboxylic acid ameliorates experimental autoimmune encephalomyelitis by blocking chemokine-mediated pathogenic cell migration and infiltration, J. Immunol. 190 (2013) 1017-1025.

[44] Z.Q. Zhao, C.D. Morris, J.M. Budde, N.P. Wang, S. Muraki, H.Y. Sun, R.A. Guyton, Inhibition of myocardial apoptosis reduces infarct size and improves regional contractile dysfunction during reperfusion, Cardiovasc. Res. 59 (2003) 132-142.

[45] M. Ziche, L. Morbidelli, Nitric oxide and angiogenesis, J. Neuro-Oncol. 50 (2000) 139-148. 